\title{
Üniversite öğrencilerinin tamamlayıcı ve alternatif tedavi yöntemlerini kullanma durumları
}

\author{
The status of college students about using complementary and alternative treatment \\ methods
}

Tuğba Solmaz, Birsen Altay

\section{Özet}

Amaç: Araştırma Sağlık Yönetimi Bölümü öğrencilerinin tamamlayıcı ve alternatif tedavi (TAT) yöntemlerini kullanma durumlarını değerlendirmek amacıyla planlanmıştır.

Gereç ve yöntem: Tanımlayıcı araştırma ilkelerine uygun olarak yapılan çalışma 25 Mayıs-15 Haziran 2017 tarihleri arasında yürütülmüştür. Araştırmanın evrenini 216 birey oluşturmaktadır ve gönüllü 190 öğrenci araştırma kapsamına alınmıştır. Araştırmanın verileri "Bilgi Toplama Formu” kullanılarak yüz yüze görüşme yöntemiyle toplanmıştır. Verilerin değerlendirilmesinde sayı, yüzdelik ve ki-kare testi kullanılmıştır.

Bulgular: Öğrencilerin \%43,7'si 18-20 yaş grubunda, \%72,6'sı kadın olup, \%89,5'i TAT yöntemi kullanmaktadır. Öğrencilerin \%42,5'inin beden ve zihin tedavilerini, \%34,5'inin vücut terapilerini, \%12,4'ünün alternatif ve medikal sistemlerini ve $\% 10,4$ 'ünün enerji ve manipülatif tedavilerini kullandıkları tespit edilmiştir. Bu yöntemleri \%55,9'unun internet, \%33,5'inin arkadaş ve \%12,4'ünün ise akraba/ komşu aracılığıyla öğrendikleri belirlenmiştir. Çalışmamızda öğrencilerin \%94,7'sinin TAT konusunda daha önce hiç eğitim almadığı ve \%81,8'inin TAT hakkında bilgi almak istediği belirlenmiştir.

Sonuç: Çalışma sonuçları öğrencilerin yarıdan fazlasının TAT kullanmasına rağmen konuyla ilgili sağlık çalışanlarından yeterli bilgi almadıklarını göstermektedir. Son yıllarda TAT kullanımı giderek daha popüler olmaktadır. TAT yöntemlerini kullanmada internet ya da televizyon yönlendirmesi ön plana çıktığından, öğrencilere yönelik eğitimlerin fayda sağlayacağı düşünülmektedir. Ayrıca, bu çalışma konusuyla ilgili olarak daha geniş örneklemlerin değerlendirileceği çalışmaların yapılması önerilmektedir.

Anahtar Kelimeler: Tamamlayıcı ve alternatif tedavi, öğrenci.

Tuğba Solmaz, Birsen Altay. Üniversite öğrencilerinin tamamlayıcı ve alternatif tedavi yöntemlerini kullanma durumları. Pam Tıp Derg 2019;12:387-393.

\begin{abstract}
Purpose: This study has been conducted to assess health management department students' status about using complementary and alternative treatment methods (CAM).

Materials and methods: The study was conducted in compliance with descriptive research methods between 25 May 2017 and 15 June 2017. The target population of the study consisted of 216 individuals and 190 volunteer students have been taken into scope of the research. Data of the research has been collected by face-to-face interview method by using a "Data Collection Form". Assessment of the data was done by number, percentage, and chi-square tests.

Results: In total, $43.7 \%$ of the students are in the age group of $18-20,72.6 \%$ of them are female, and $89.5 \%$ of them use CAM. It has been detected that $42.5 \%$ of the students use physical and mental treatments, $34.5 \%$ of them use physical therapies, $12.4 \%$ use alternative and medical systems, and $10.4 \%$ of them use energy and manipulative treatments. It has been determined that $55.9 \%$ of them have learnt about these methods from the internet, $33.5 \%$ of them from a friend, and $12.4 \%$ of them from a relative/ neighbor. Also, $94.7 \%$ of the students have never been trained in CAM and $81.8 \%$ of them have expressed that they want to be trained.

Conclusion: The research outcomes indicate that more than half of the students implement CAM. However, they do not seek enough information on this issue from healthcare professionals. In recent years, use of CAM is becoming increasingly popular. Since guidance of internet or television stands out in use of CAM methods, it is considered that trainings for students shall benefit. Also, with regard to this study, it is recommended that larger samples be undertaken to evaluate.
\end{abstract}

Key Words: Complementary and alternative treatment, student.

Tuğba Solmaz, Birsen Altay. The status of college students about using complementary and alternative treatment methods. Pam Med J 2019;12:387-393.

Tuğba Solmaz, Öğr. Gör. Tokat Gaziosmanpaşa Üniversitesi İlk ve Acil Yardım Bölümü, TOKAT, e-posta: tugbasolmaz.gou@gmail.com, (orcid. org/0000-0003-0574-0035) (Sorumlu yazar)

Birsen Altay, Doç. Dr. Ondokuz Mayıs Üniversitesi, Sağlık Bilimleri Fakültesi, Halk Sağlığı Hemşireliği Anabilim Dalı, SAMSUN, e-posta: baltay@ omu.edu.tr, (orcid.org/0000-0001-5828-1117) 


\section{Giriş}

Bilimsel tedavilerin dışında kalan birçok tedavi TAT olarak tanımlanmaktadır [1]. Dünya Sağlık Örgütü (DSÖ), TAT'ı modern tıp dışındaki uygulamalar olarak tanımlamış olsa da; iki kavramı birbirinden ayırmak daha doğrudur [2]. Tamamlayıcı tedavi, destek amaçı bilimsel tıpla birlikte kullanılan ve bilimsel tıbbın etkisini azaltmayan tedavi olarak tanımlanmaktadır. Oysa alternatif tedavi, tıp dışı uygulamalar olarak kullanılan ve bilimsel olarak etkisi kanıtlanmamış tedavi şekli olarak ifade edilmektedir [3].

Literatürde TAT yöntemlerinin 1990'। yıllardan sonra yaygın kullanılmaya başlandığı görülmektedir [4]. Dünya genelinde kullanımda olan TAT yöntemleri beş grup olarak sınıflandırılmaktadır. Bunlar; biyolojik temelli, zihin-beden etkileşimi, enerji, manipülatif ve vücut bazlı terapilerdir [5]. Alternatif tedavilerin etkinliğine yönelik sınırı sayıda kanıt olmasına rağmen dünya genelinde kullanımının arttığı görülmektedir. Türkiye'de de, tıp dışı alternatif tedavi kullanımı önemli ölçüde yaygındır [6].

Tamamlayıcı ve alternatif tıbbi tedaviler, yetişkinler tarafından sıklıkla kullanılmaktadır. Amerika'da yapılan bir çalışmada, TAT kullanımı \%33,8 iken, bu oran 1997'de \%42,1'e yükselmiştir [7]. Yapılan başka bir çalışmada ise; yetişkinlerde TAT kullanım sıklığının arttığı ve \%9 ile \%65 arasında değiştiği ifade edilmiştir [8]. Literatür kronik hastalığı olan kişilerin hastalık tanılama sürecinde, modern tedavi yöntemleriyle birlikte ya da tek başına TAT yöntemlerine başvurduğunu belirtmektedir [9].

Bireyler ilaçların yan etkilerini azaltmak, bağışıklıksisteminigüçlendirmek, umutsuzluktan kurtulmak, sağlıklı davranışlar kazanmak, gerginlik ve kontrol kaybından kaçınmak için TAT kullandıklarını ifade etmektedir. Ayrıca insanların sağlık ve diğer konulardaki değerleri ve inançları onların TAT kullanımını etkileyen önemli faktörler olarak görülmektedir [10, 11]. Türkiye'de bireyler arasında çok çeşitli yöntemler kullanılmakla beraber bu yöntemlerin ne olduğu, ne sıklıkta kullanıldığı ve öğrencilerin bu konudaki yaklaşımına yönelik çalışmalar sınırlı sayıdadır [12].

Bu araştırma, Sağlık yönetimi bölümü öğrencilerinin TAT hakkındaki bilgi, tutum ve davranışlarını değerlendirmek amacıyla yapılmıştır.

\section{Gereç ve yöntem}

Tanımlayıcı kesitsel türde olan araştırma 25 Mayıs-15 Haziran 2017 tarihleri arasında bir devlet üniversitesinin Sağlık Yönetimi bölümünde okuyan öğrencilerle yapılmıştır. Evrenin tamamına ulaşılmaya çalışılmıştır. Anket formu araştırmanın uygulanacağı günlerde okula gelen 210 öğrenciye dağıtılmıştır. Çalışmaya katılmayı kabul etmeyen (12 öğrenci) ve eksik bırakılan anketler (8 öğrenci) çalışma dışı bırakıımıştır. Çalışma, gönüllü olarak anket formunu doldurmayı kabul eden 190 öğrenciyle tamamlanmıştır. Verilerin toplanması için araştırmacılar tarafından literatüre dayalı hazırlanan 25 soruluk anket formu kullanılmıştır. Anket formu iki bölümden oluşmaktadır. Birinci bölümde öğrencilerin sosyodemografik özelliklerini içeren sekiz soru, ikinci bölümde ise öğrencilerin TAT olarak kullandıkları yöntemleri ve bu yöntemlere ilişkin bilgi, tutum ve davranışlarını içeren 17 soru yer almaktadır. Veriler araştırmacı tarafından yüz yüze görüşme yöntemi ile toplanmıştır. Anket formunun doldurulması yaklaşık 15-20 dakika sürmüştür.

Araştırmanın yürütülebilmesi için 25 Mayıs 2017 tarihinde 45428382-050/50712 sayılı etik kurul onayı ve ilgili üniversite müdürlüğünden yazııı izin alınmıştır. Öğrencilere bilgilerin gizli kalacağı konusunda açıklama yapıımış ve 'bilgilendirilmiş onam formu' koşulu etik ilke olarak yerine getirilmiştir.

\section{İstatistiksel analiz}

Veriler SPSS 20,0 istatistik programında değerlendirilmiştir. Tanımlayıcı istatistikler, sayı, yüzde, ki-kare testi kullanılmıştır. Karşılaştırmalarda $p<0,05$ değeri istatistiksel olarak anlamlı kabul edilmiştir.

\section{Bulgular}

Araştırmaya katılan öğrencilerin \%72,6'sı kadın, \%27,4'ü erkektir. Öğrenciler 18-28 aralığında olup, $20,54 \pm 1,75$ yaş ortalamasına sahiptirler. TAT yöntemlerini kullanma durumları değerlendirildiğinde ise, çoğunluğunun $(\% 89,5)$ TAT yöntemlerini kullandığı görülmektedir (Şekil 1). 


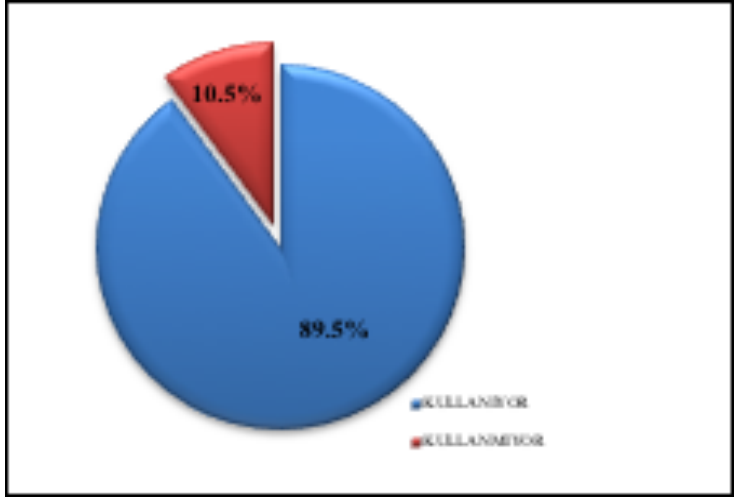

Şekil 1. Sağlık Yönetimi Bölümü öğrencilerinin TAT Kullanma Durumu, 2017.

Çalışmamızda öğrencilerin \%94,7'sinin TAT konusunda daha önce hiç eğitim almadığı ve \%81,8'inin TAT hakkında bilgi almak istediği belirlenmiştir. Öğrencilerin \%71,0'i TAT kullanımını tıbbi tedavi kadar etkili olarak düşünmekte, \%67,6'sı kullandığı yöntemi yararlı bulmakta ve $\% 86,5$ 'i ise TAT kullanımını başkalarına tavsiye etmektedir.

Öğrencilerin tercih ettikleri TAT yöntemleri arasından $\% 42,5$ 'inin beden ve zihin tedavilerini, $\% 34,5$ 'inin vücut bazlı terapileri, \%12,4'ünün biyolojik temelli ve \%10,4'ünün de enerji ve manipülatif tedavileri kullandıkları tespit edilmiştir. Öğrencilerin bu yöntemleri kullanma nedenleri değerlendirildiğinde, \%52,9'u stresi azaltmak, \%25,2'si yaşam kalitesini artırmak ve \%23,5'i de sağlık problemleri için kullandığını ifade etmiştir. Çalışmamızda öğrencilerin TAT yöntemleri konusundaki bilgiyi internet $(\% 55,9)$, arkadaş $(\% 33,5)$, sağlık personeli $(\% 18,2)$ ve akraba/komşu $(\% 12,4)$ aracılığıyla öğrendikleri tespit edilmiştir (Tablo 1).

Öğrencilerin cinsiyet, ikamet edilen yer, gelir durumu, sosyal güvence ve kronik hastalık durumu ile TAT kullanımı arasındaki ilişki değerlendirildiğinde; aradaki ilişki istatistiksel olarak anlamlı bulunmamıştır $(p>0,05)$. Öğrencilerde yaş ve öğrenim görülen sınıf düzeyi ile TAT kullanımı arasındaki ilişki değerlendirildiğinde ise yaş ve sınıf düzeyi arttıkça, TAT kullanımının da artığı görülmektedir ve aradaki ilişki istatistiksel olarak anlamlı bulunmuştur $(p<0,05)$ (Tablo 2 ).

Tablo 1. Sağlık Yönetimi Bölümü öğrencilerinin TAT kullanım özellikleri, (n=190), 2017.

\begin{tabular}{|c|c|c|}
\hline Özellikler & Sayı & $\% *$ \\
\hline $\begin{array}{l}\text { Kullanılan TAT yöntemi }(\mathbf{n = 1 7 0 )} \\
\text { Beden ve zihin tedavileri } \\
\text { Vücut terapileri } \\
\text { Alternatif ve medikal sistemler } \\
\text { Enerji tedavileri }\end{array}$ & $\begin{array}{l}72 \\
59 \\
21 \\
18\end{array}$ & $\begin{array}{l}42,5 \\
34,5 \\
12,4 \\
10,4\end{array}$ \\
\hline $\begin{array}{l}\text { TAT yöntemi ile ilgili bilgi alma durumu } \\
\text { Evet } \\
\text { Hayır }\end{array}$ & $\begin{array}{c}9 \\
161\end{array}$ & $\begin{array}{c}5,3 \\
94,7\end{array}$ \\
\hline $\begin{array}{l}\text { TAT yöntemi ile ilgili bilgi kaynağı * }(\mathbf{n}=170) \\
\text { İnternet } \\
\text { Arkadaş } \\
\text { Sağlık personeli } \\
\text { Akraba/komşu } \\
\text { TV/radyo } \\
\text { Gazete/dergi }\end{array}$ & $\begin{array}{l}95 \\
57 \\
31 \\
21 \\
19 \\
15\end{array}$ & $\begin{array}{l}55,9 \\
33,5 \\
18,2 \\
12,4 \\
11,2 \\
8,8\end{array}$ \\
\hline $\begin{array}{l}\text { TAT yöntemi ile ilgili eğitim alma isteği } \\
\text { Evet } \\
\text { Hayır }\end{array}$ & $\begin{array}{r}139 \\
31\end{array}$ & $\begin{array}{l}81,8 \\
18,2\end{array}$ \\
\hline $\begin{array}{l}\text { TAT yöntemi uygulama nedenleri }(\mathbf{n}=170) \\
\text { Stresi azaltmak } \\
\text { Yaşam kalitesini artırmak } \\
\text { Sağlık problemlerine çözüm bulmak için }\end{array}$ & $\begin{array}{l}90 \\
43 \\
40\end{array}$ & $\begin{array}{l}52,9 \\
25,2 \\
23,5\end{array}$ \\
\hline $\begin{array}{l}\text { Kullanılan TAT yönteminin etkisine inanma }(n=170) \\
\text { Evet } \\
\text { Hayır }\end{array}$ & $\begin{array}{r}126 \\
44\end{array}$ & $\begin{array}{l}74,1 \\
25,9\end{array}$ \\
\hline
\end{tabular}

TAT: Tamamlayıcı ve alternatif tedavi.

*Birden fazla cevap seçeneği işaretlenmiştir. Yüzdeler " $h$ " üzerinden alınmıştır. 
Tablo 2. Sağlık Yönetimi Bölümü öğrencilerinin TAT kullanma durumlarına ilişkin bazı özelliklerinin dağılımı, ( $n=190), 2017$.

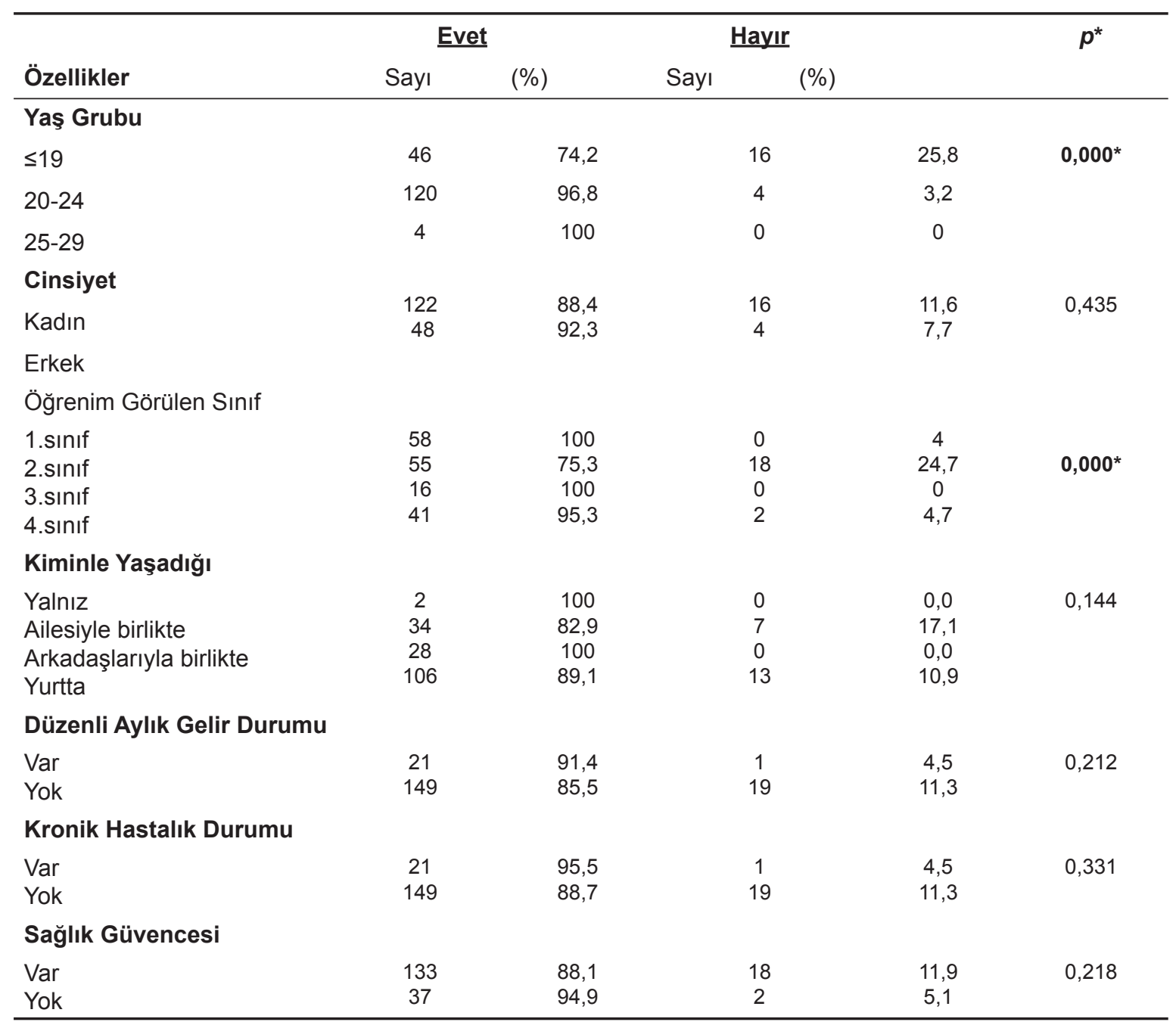

TAT: Tamamlayıcı ve alternatif tedavi.

*Ki-kare testi kullanılmıştır ve istatistiksel olarak anlamlıdır.

\section{Tartışma}

Son yıllarda sağlık sorunlarının çözümüne yönelik tıp dışı alternatif tedavi yöntemlerin kullanımı artmaya devam etmektedir. Çalışmamızda öğrencilerin çoğunluğu $(\% 89,5)$ tamamlayıcı ve alternatif tedavileri kullanmaktadır. Sönmez ve ark.'nın (2018) çalışmasında öğrencilerde TAT kullanımı $\% 50,0$ olarak bulunmuştur [13]. Araz ve ark.'nın (2012) çalışmasında TAT kullanım sıklığı $\% 61,2$ olarak bulunmuştur [14]. Tan ve ark. (2004) tarafından yapılan bir çalışmada ise 18 yaş ve üzeri erişkinlerin TAT kullanım oranı $\% 70,0$ olarak bulunmuştur [15]. Malezya'da yapılan bir çalışmada da öğrencilerin yarıdan fazlasının TAT kullandığı bildirilmektedir [16]. TAT uygulamalarının en yaygın kullanılma gerekçesi olarak doğal olması ve sağlığa zarar vermeyeceği algısı bireylerde TAT kullanımını artırmaktadır [17]. Çalışmamızda öğrencilerin \%67,6'sı kullandığı yöntemi yararlı bulmaktadır. Yıldırım ve ark. (2010) tarafından yapılan bir çalışmada sağlık bölümü öğrencilerinin çoğunluğunun tıp dışı tedavileri yararlı bulduğu görülmektedir [18]. Araz ve ark.'nın (2012) çalışma bulgusu da bizim çalışma bulgumuzla benzer yöndedir [14].

Çalışma kapsamındaki öğrencilerin $\% 42,5$ 'inin beden ve zihin tedavilerini, \%34,5'inin ise vücut terapilerini yaygın olarak kullandıkları belirlenmiştir. Doğanay ve ark.'nın (2018) yaptığı çalışmada beden ve zihin tedavilerinden dini yöntemler/ dua $(\% 32,3)$, masaj $(\% 27,5)$, vitamin kullanımı $(\% 24,0)$ ve bitkisel tedavi 
(\%21,4) olduğu bulunmuştur [19]. Yapılan başka çalışmalarda da öğrenciler arasında en çok dua ve masaj kullanımı rapor edilmiştir [18-20].

Katılımcı öğrencilerin \%52,9'u stresi azaltmak amacıyla bu yöntemleri kullandıklarını ifade etmiştir. Doğanay ve ark.'nın (2018) yaptığı çalışmada ise TAT yöntemlerini kullanma sebeplerinin daha çok "rahatlama amaçlı" $(\% 35,0)$ olduğu bulunmuştur ve çalışma bulgumuzu destekler niteliktedir [19]. Literatürde de çeşitli ülkelerde hastalıkları önlemek veya tedavi etmek, fiziksel olarak rahatlamak ve psikolojik olarak daha iyi hissetmek için TAT yöntemlerinin kullanıldığı bildirilmektedir [2124].

Çalışmamızda öğrenciler TAT yöntemleri konusundaki bilgiyi daha çok internet $(\% 55,9)$ aracılığıyla öğrendiklerini ifade etmişlerdir. Doğanay ve ark.'nın (2018) çalışmasında öğrencilerin \%52,4'ünün, Açıkgöz ve ark.'nın (2016) çalışmasında ise öğrencilerin \%56,4'ünün TAT yöntemleri hakkındaki bilgiye internetten ulaştıkları görülmektedir. Yapılan farklı çalışmalarda da TAT yöntemleri hakkında bilgi edinmede aynı kaynakların kullanıldığı belirtilmektedir $[19,25,26]$. Çalışmamızda internet aracılığıyla bu yöntemleri öğrenme oranının diğer bilgi edinme kaynaklarına göre daha yüksek oluşu üniversite öğrencileri arasında internet kullanımının fazla olmasına bağlanabilir.

Çalışmaya katılan öğrencilerin \%94,7'si daha önce TAT konusunda hiç eğitim almadığını ifade etmektedir. Yapılan başka bir çalışmada da öğrencilerin TAT kullanımı hakkında yeterli bilgiye sahip olmadığı bildirilmektedir [19]. TAT kullanımının yüksek olduğu çalışmamızda, öğrencilerin çoğunluğunun TAT yöntemleri hakkında eğitim almamış olması ve \%81,8'inin de bu konuda eğitim almak istediğini ifade etmesi, öğrencilerin bu konuda olumlu görüşe sahip olduklarını göstermektedir.

Öğrencilerde yaş ve öğrenim görülen sınıf düzeyi ile TAT kullanımı arasındaki ilişki değerlendirildiğinde ise yaş ve sınıf düzeyi arttıkça, TAT kullanımının da arttığı görülmektedir. Bishop ve Lewith (2010) literatür taraması yoluyla TAT alanında yapılmış 161 çalışmanın 98 tanesinde (\%61) yaşın TAT kullanımının anlamlı bir yordayıcısı olduğunu ortaya koymuştur [27]. Oldendick ve ark. (2000) da yaptıkları çalışmada yaşın TAT uygulamalarından yararlanma ile ilişkisi olduğunu ortaya koymaktadır [28]. Genç yaş grubunda yer alan 18 yaş ve üzeri öğrencilerle yapılan çalışmamızda, yaş düzeyi arttıkça TAT kullanımı da artmaktadır ve öğrenciler bu tedavileri daha çok stresle mücadele etmek amaçlı kullandıklarını ifade etmektedir. Çalışmamızda 2. sınıf öğrencilerinin daha çok TAT kullanımına başvurmaları ise; öğrencilerin çoğunluğunun bu sınıfta yer almaları, TAT kullanımı konusunda internet kullanımlarının fazla olması ve yöntemlerin kullanımı konusunda birbirinden etkilenmeleri ile açıklanabilir.

Yapılan çalışmalar değerlendirildiğinde; en yaygın TAT kullanıcılarının yaş aralığının 39-65 olduğu öne sürülmektedir [29]. Bulduklu 2014 yılında yaptığı çalışmada TAT'a başvuran kişilerin \%48,8'inin 40-60 yaş arasında olduğunu belirtmiştir [30]. Yaşlı bireylerin TAT yöntemlerini fiziksel olarak kendilerini rahatlattığına inandıkları için kullandıkları saptanmıştır [31]. Gençlere oranla yaşlı bireylerde TAT kullanımın artması, yaşla birlikte kronik hastalıkların ve çoklu ilaç kullanımın artmasına bağlı modern tıbbi uygulamalardan yarar görmeyen yaşlı bireylerin çözümü daha çok TAT kullanımında aramaları ile ilişkilendirilebilir.

Çalışmamızda eğitim görülen sınıf düzeyi arttıkça TAT kullanımının da arttığı görülmektedir. Yapılan çalışmalarda da eğitim düzeyi yükseldikçe kişilerin TAT kullanımının olumlu yönde arttığı belirlenmiştir [32, 33]. Literatür bulguları çalışmamızı destekler niteliktedir.

Sonuç olarak çalışmamızda sağlık yönetimi bölümü öğrencilerinin önemli bir kısmının TAT yöntemlerini kullandıkları belirlenmiştir. Son yıllarda sağlık sorunlarına yönelik çözüm konusunda TAT yöntemlerinin yaygın ve popüler olduğu görülmektedir. $\mathrm{Bu}$ nedenle öğrencilerin TAT yöntemlerinin etkisi ve riskleri konusunda bilgilendirilmeleri önerilmektedir. Çalışma bulguları ışığında TAT yöntemlerini kullanmada internet yönlendirmesi ön planda olduğundan televizyon ya da internet gibi ortamların denetimlerinin yapılmasının faydalı olacağı düşünülmektedir.

Çalışmamız tek bir bölümde öğrenim gören sınırlı sayıda öğrenci ile yürütülmüştür. Bu nedenle, üniversite öğrencilerinin TAT kullanımı 
hakkındaki tutumlarını genelleme yapabilecek şekilde belirleyebilmek için daha geniş çaplı araştırmaların yapılması önerilmektedir.

\section{Çıkar İlişkisi: Yazarlar çıkar ilişkisi olmadığını beyan eder.}

\section{Kaynaklar}

1. Khorshid L, Yapucu Ü. Tamamlayıcı tedavilerde hemşirenin rolü. Atatürk Üniversitesi Hemşirelik Yüksekokulu Dergisi 2005;8:124-130.

2. National center for complementary and alternative medicine (NCCAM). Complementary, alternative or integrative health: what's in a name. Available at: http:// nccam.nih.gov/health/whatiscam/. Erişim tarihi 13 Ocak 2019. (Accessed January 13, 2019).

3. Kav S, Hanoğlu Z, Algier, L. Türkiye'de kanserli hastalarda tamamlayıcı ve alternatif tedavi yöntemlerinin kullanımı: literatür taraması. Uluslararası Hematoloji Onkoloji Dergisi 2008;18:32-38.

4. Erdoğan Z, Çınar S. Reiki: Eski bir iyileștirme sanatımodern hemșirelik uygulaması. Kafkas J Med Sci 2011;1:86-91. https://doi.org/10.5505/kjms.2011.70288

5. Demirci GT, Altunay İ, Küçükünal $A$, ve ark. Deri hastalıklarında tamamlayıcı ve alternatif tıbbi yöntem kullanımı ve hastalar üzerindeki olumlu ve olumsuz etkileri. Turk J Dermatol 2012;6:150-154. https://doi. org/10.5152/tdd.2012.32

6. Çetin OB. Eskişehir'de tamamlayıcı ve alternatif tıp kullanımı. Sosyoekonomi 2007;2:89-106.

7. Eisenberg DM, Davis RB, Ettner SL, et al. Trends in alternative medicine use in the united states, 19901997: results of a follow-up national survey. JAMA 1998;280:1569-1575.

8. ErnstE, Cassileth BR. The prevalence of complementary/ alternative medicine in cancer: a systematic review. Cancer 1998;83:777-782.

9. Dikici A, Ulaşlı AM, Çevik H, Eroğlu S, Solak Ö, Dündar Ü. Dejeneratif osteoartrit tanılı hastalarda tamamlayıcı ve alternatif tıp kullanımı. Euras J Fam Med 2015;4:126130.

10. Tokem Y. Astımlı hastalarda tamamlayıcı ve alternatif tedavi kullanımı. Tüberküloz ve Toraks Dergisi 2006;54:189-196.

11. Özçelik H, Fadıloğlu Ç. Kanser hastalarının tamamlayııı ve alternatif kullanım nedenleri. Türk Onkoloji Dergisi 2009;24:48-52.

12. Çevik K, Bolsoy N, Beler M. Hemşirelerin tamamlayıcı ve alternatif tedaviye ilişkin bilgi ve görüşleri. Uluslararası Hakemli Hemşirelik Araştırmaları Dergisi 2016;6:1-15.
13. Sönmez $\mathrm{Cl}$, Başer Ayhan D, Küçükdağ HN, Kayar O, Acar I, Güner Döner P. Tıp Fakültesi öğrencilerinin geleneksel ve tamamlayıcı tıp ile ilgili bilgi durumlarının ve davranışlarının değerlendirilmesi. Konuralp Tıp Dergisi 2018;10:276-281. https://doi.org/10.18521/ ktd. 455208

14. Araz Çöl N, Taşdemir HS, Kılıç Parlar S. Sağlık Bilimleri Fakültesi öğrencilerinin tıp dışı alternatif ve geleneksel uygulamalar konusundaki görüşlerinin değerlendirilmesi. Gümüşhane Üniversitesi Sağlık Bilimleri Dergisi 2012;1:239-251.

15. Tan M, Uzun Ö, Akçay F. Trends in complementary and alternative medicine in eastern Turkey. J Altern Complement Med 2004;10:861-865.

16. Hasan SS, Yong CS, Babar MG, et al. Understanding, perceptions and self-use of complementary and alternative medicine (CAM) among Malaysian pharmacy students. BMC Complement Altern Med 2011;11:95. https://doi.org/10.1186/1472-6882-11-95

17. Udo IA, Bassey OI, Bassey US, Akpan IV. Clinical and socio demographic profiles of complementary and alternative medicine users among outpatient clinic attendees in UYO, South-South Nigeria, Fam Med Med Sci Res 2014;3:1-5. https://doi.org/10.4172/23274972.1000117

18. Yıldırım Y, Parlar S, Eyigor S. ve ark. An analysis of nursing and medical students' attitudes towards and knowledge of complementary and alternative Medicine (CAM). J Clin Nurs 2017;19:1157-1166. https://doi. org/10.1111/j.1365-2702.2009.03188.x

19. Doğanay S, Güzel D, Öztürk D, Tanyeli A. Tamamlayıcı ve alternatif tıp: Türk Sağlık Bilimleri ve Tıp öğrencileri arasında bilgi, tutum ve kullanma durumları. J Contemp Med 2018;8:48-54. https://doi.org/10.16899/ gopctd. 414746

20. Açıkgöz A, Kaya Y, Özkaraman A, Balcı Alparslan G, Babadağ B, Çolak E. Sağlık Yüksekokulu öğrencilerinin tamamlayıcı ve alternatif tıbbı bilme ve kullanma durumu. Gümüşhane Üniversitesi Sağlık Bilimleri Dergisi 2016;5:12-21.

21. Astin JA, Marie A, Pelletier KR, Hansen E, Haskell WL. $A$ rewiev of the incorporation of complementary and alternative medicine by mainstream physicians. Arch Intern Med 1998;158:2303-2310.

22. Özkan A. Çocukluk çağı kanserlerinde tamamlayıcı ve alternatif tıp. Klinik Gelişim 20007;20:179-180.

23. Sirois FM. Provider-based complementary and alternative medicine use among three chronic illness groups: associations with psychosocial factors and concurrent use of conventional health-care services. Complement Ther Med 2008;16:73-80. https://doi. org/10.1016/j.ctim.2007.03.006

24. Uğurluer G, Karahan A, Edirne T, Şahin HA. Ayaktan kemoterapi ünitesinde tedavi alan hastaların tamamlayıcı ve alternatif tıp uygulamalarına başvurma sıklığı ve nedenleri. Van Med J 2007;1:68-73. 
25. Owen DJ, Fang MLE. Information-seeking behavior in complementary and alternative medicine (CAM): An online survey of faculty at a health sciences campus. J Med Libr Assoc 2003;91:311-321.

26. Algier L, Hanoğlu Z, Özden G, Kara F. The use of complementary and alternative (non-conventional) medicine in cancer patients in Turkey. Eur $\mathrm{J}$ Oncol Nurs 2005;9:138-146. https://doi.org/10.1016/j. ejon.2005.03.010

27. Bishop FL, Lewith GT. Who Uses CAM? A Narrative review of demographic characteristics and health factors associated with CAM use. eCAM 2010;7:11-28.

28. Oldendick R, Coker AL, Wieland D, et al. Populationbased survey of complementary and alternative medicine usage, patient satisfaction, and physician involvement. South Med J 2000;93:375-381.

29. Weizman V,Ahn E, Thanabalan R, et al. Characterisation of complementary and alternative medicine use and its impact on medication adherence in inflammatory bowel disease. Aliment Pharmacol Ther 2012;35:342-349. https://doi.org/10.1111/j.1365-2036.2011.04956.x

30. Bulduklu $Y$. The motives of the patients in preferring complementary and alternative treatments within the communication context. The International Journal of Communication and Health 2014;4:59-68.

31. Bulduklu Y. Hedef kitle bağlamında tamamlayıcı ve alternatif tıp uygulamaları. Türkiyat Araştırmaları Dergisi 2015;607-627. https://doi.org/10.21563/ sutad.187051

32. Buda L, Lampek K, Tahin T. Correlations of alternative medicine, health status and health care in Hungary. Orvosi Hetilap 2002;143:891-896. https://doi. org/10.18521/td.455208

33. Liu EH, Turner LM, Lin SX, et al. Use of alternative medicine by patients undergoing cardiac surgery. J Thorac Cardiovasc Surg 2000;120:335-341.

*Bu çalışma, Uluslararası Karadeniz Hemşirelik Eğitimi Kongresinde poster olarak sunulmuştur. 